\title{
ANALYSIS OF RELATIONSHIPS FOR THE DETERMINATION OF THE AERODYNAMIC FORCES ACTING ON PARTICLES IN A GAS-DISPERSED FLOW
}

\author{
Institute of Technical Mechanics \\ of the National Academy of Sciences of Ukraine and the State Space Agency of Ukraine \\ 15 Leshko-Popel St., 49005,Dnipro, Ukraine; e-mail: knyshenko@ukr.net
}

The aim of this work is to analyze existing analytical and empirical relationships for determining the forces acting on a solid particle in a gas flow which are caused by its rotation (the Magnus force) and the gradient of the carrying gas velocity (the Saffman force). These forces act transversely to the velocity of a particle in a gas flow with restricting walls, and their effect is crucial in terms of the adequacy of calculation of the particle trajectory parameters. The paper analyzes relationships for Magnus and Saffman force determination obtained analytically or by mathematical treatment of experimental data and limited by certain values of criterion parameters. The force determination criteria are the Reynolds numbers based on the particle diameter and flow-past velocity $\left(R e_{d}\right)$, on the square of the particle diameter and the particle rotation angular velocity $\left(R e_{\omega}\right)$, and on the particle diameter and the gradient of the carrier gas local velocity. Particle rotation and the Magnus force are caused by inelastic collisions of particles with restricting surfaces (walls). Comparative calculations on Magnus force determination by the relationships under analysis give contradictory results at comparable values of the determining criteria, thus calling for a thorough analysis of the validity of their use in specific conditions. The Saffman force reaches its maximum in gas flow regions with a high velocity gradient (in the vicinity of a restricting surface). The calculations by the relationships for Saffman force determination showed a far narrower spread in comparison with the case of the Magnus force. A specific numerical example with particles of different diameters is considered to show the ranges of variation of the determining Reynolds criteria in the process of motion of a particle in a turbulent carrying gas flow in a two-dimensional channel. The results obtained may be used in numerical simulation of gas-dispersed flows in channels and in the vicinity of restricting surfaces.

Keywords rotation, velocity gradient, Reynolds criteria, carrying gas, analytical relationships, Magnus force, Saffman force, particle.

1. Shraiber A. A., Milyutin V. N., Yatsenko V. P. Hydromechanics of Two-Component Flows with a Solid Polydisperse Substance (in Russian). -Kyiv: Naukova Dumka, 1980. 252 pp.

2. Sommerfeld . Analysis of collision effects for turbulent gas-particle flow in a horizontal channel: Part I. Particle transport. International Journal of Multiphase Flow. 2003. No. 29. p. 675-699. doi:10.1016/S03019322(03)00031-4

3. Sommerfeld $M$, Lain $S$. Analysis of dilete phase pneumatic conveying through pipe systems by the Euler/Lagrange approach. Ninth International Conference on CFD in the Minerals and Process Industries CSIRO, Melbourne, Australia, December 10-12, 2012. Pp. 1-12.

4. Lain S. Study of turbulent two-phase gas-solid flow in horizontal channels. Indian Journal of Chemical Technology. 2013. V. 20. Pp. 128-136.

5. Souza F. J, Silva L., Utzig J. Gas-particle flow in a diffuser. 22nd International Congress of Mechanical Engineering, November 3-7, 2013, Ribeirao Preto, SP, Brazil. Pp. 2970-2982.

6. Gorbis Z. R. Heat Exchange and Hydromechanics of Dispersed Through Flows (in Russian). Moscow: Energiya, 1970. $424 \mathrm{pp}$.

7. Naumov V. A. Dynamics of the disperse particle in the viscous environment (in Russian). Matem. Mod. 2006. V. 18. No. 5. Pp. 27-36.

8. Rubinov S. L., Keller J. B. The transverse force on a spnning sphere moving in a viscous fluid. J. Fluid Mech. 1961. V. 11, No. 3. Pp. 447-459.

9. Nigmatullin R. I. Basics of Heterogeneous Media Mechanics (in Russian). Moscow: Nauka, 1978. 336 pp.

10. Varaksin A. Yu. Turbulent Flows of a Gas with Solid Particles (in Russian). Moscow: Fizmatlit, 2003. 192 pp.

11. Yatsenko V. P., Aleksandrov V. V. Magnus force measurement at moderate Reynolds numbers (in Russian). Prykladna Mekhanika. 2001. V. 3 (75). No. 3. Pp. 83-87.

12. Saffman P. G. The lift on a small sphere in a slow shear flow.J. Fluid Mech. 1965. V. 22. No. 2. Pp. 385-400.

13. Asmolov E. S. Transversal Migration of Spherical Particles in Shear Unstready Flows (in Russian). D. Sc. thesis. Moscow, 2015. $189 \mathrm{pp}$.

14. Yatsenko V. P. Determination of the force acting on a spherical solid particle in a shear flow (in Russian). Physics of Aerodisperse Systems (collected papers). 2002. Iss. 39. Odessa: Astroprint. Pp. 240-247.

15. Dandy $D$. S. A sphere in shear flow at finite Reynolds number: effect of shear on particle lift, drag and heat transfer. J. Fluid Mech. 1990. V. 216. Pp. 381-410.

16. McLaughlin J. B. Inertial migration of a small sphere in linear shear flows. J. Fluid Mech. 1991. V. 224. Pp. 261-274. 
17. Sow S. Hydrodynamics of Multiphase Systems (in Russian). Moscow: Mir, 1971. 536 pp.

18. Timoshenko V. I., Knyshenko Yu. V., Shcherbakov V. I. Special features of effects of sizes of gas-dispersive flow particles on their interactions with channel walls (in Russian). Teh. Meh. 2016. No. 3, Pp. $24-34$.

Received on May 13, 2019, in final form on June 20, 2019 